\title{
An audit of the screen-and-treat intervention to reduce cryptococcal meningitis in HIV-positive patients with low CD4 count
}

\begin{tabular}{|c|c|}
\hline \multicolumn{2}{|c|}{$\begin{array}{l}\text { Authors: } \\
\text { Egide Ndayishimiye }^{1} \text { } \\
\text { Andrew J. Ross }{ }^{2}\end{array}$} \\
\hline \multicolumn{2}{|c|}{$\begin{array}{l}\text { Affiliations: } \\
{ }^{1} \text { Health, College of Health } \\
\text { Sciences, University of } \\
\text { KwaZulu-Natal, Prince } \\
\text { Mshiyeni Memorial Hospital, } \\
\text { South Africa }\end{array}$} \\
\hline \multicolumn{2}{|c|}{$\begin{array}{l}{ }^{2} \text { Department of Family } \\
\text { Medicine, School of Nursing } \\
\text { and Public Health, College of } \\
\text { Health Sciences, University of } \\
\text { KwaZulu-Natal, South Africa }\end{array}$} \\
\hline \multicolumn{2}{|c|}{$\begin{array}{l}\text { Corresponding author: } \\
\text { Egide Ndayishimiye, } \\
\text { ndegide@hotmail.com }\end{array}$} \\
\hline \multicolumn{2}{|c|}{$\begin{array}{l}\text { Received: } 28 \text { Feb. } 2018 \\
\text { Accepted: } 05 \text { May } 2018 \\
\text { Published: } 08 \text { Aug. } 2018\end{array}$} \\
\hline \multicolumn{2}{|c|}{$\begin{array}{l}\text { How to cite this article: } \\
\text { Ndayishimiye E, Ross AJ. An } \\
\text { audit of the screen-and-treat } \\
\text { intervention to reduce } \\
\text { cryptococcal meningitis in } \\
\text { HIV-positive patients with } \\
\text { low CD4 count. Afr J Prm } \\
\text { Health Crae \& Fam Med. } \\
\text { 2018;10(1). a1779. https:// } \\
\text { doi.org/10.4102/phcfm. } \\
\text { v10i1.1779 }\end{array}$} \\
\hline \multicolumn{2}{|c|}{$\begin{array}{l}\text { Copyright: } \\
\text { (c) 2018. The Authors. } \\
\text { Licensee: AOSIS. This wo } \\
\text { is licensed under the } \\
\text { Creative Commons } \\
\text { Attribution License. }\end{array}$} \\
\hline \multicolumn{2}{|l|}{ Read online: } \\
\hline 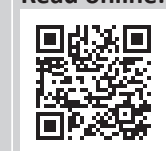 & $\begin{array}{l}\text { Scan this QR } \\
\text { code with your } \\
\text { smart phone or } \\
\text { mobile device } \\
\text { to read online. }\end{array}$ \\
\hline
\end{tabular}

Background: HIV-associated cryptococcal meningitis (CCM) and related mortality may be prevented by the effective implementation of a screen-and-treat intervention.

Aim: The aim of this study was to assess the effectiveness of the screen-and-treat intervention at a regional hospital in KwaZulu-Natal province, South Africa.

Method: This was a descriptive study in which the records of patients seen in 2015 and 2016 with a CD4 count $\leq 100$ cell $/ \mathrm{mm}^{3}$ were retrieved from National Health Laboratory Service (NHLS) records and matched against patients admitted for HIV-associated CCM.

Results: A total of 5.1\% (190 out of 3702) patients with CD4 count $\leq 100 \mathrm{cell} / \mathrm{mm}^{3}$ were cryptococcal antigen positive ( $\mathrm{CrAg}+\mathrm{ve}$ ), of whom $22.6 \%$ (43 out of 190) were admitted with CCM. Patients who were CrAg +ve had significantly lower CD4 counts (mean CD4 = $38.9 \pm 28.5$ ) when compared to CrAg -ve patients (mean CD4 $=49.9 \pm 37.4$ ) with $p=0.0001$. Only $2.6 \%$ (5 out of 190) of patients were referred for a lumbar puncture (LP) as part of the screen-and-treat intervention, whilst 38 who were CrAg +ve self-presented with CCM. Eightyeight patients were admitted for suspected CCM: eight because of the screen-and-treatintervention (none of whom had meningitis based on cerebrospinal fluid results) and 80 of whom self-presented and had confirmed CCM. The overall mortality of patients admitted with CCM was $30 \%$ (24 out of 80 ).

Conclusion: The current ad-hoc screen-and-treat intervention was ineffective in detecting patients at risk of developing CCM. Systems need to be put in place to ensure that all CrAg +ve patients have an LP to detect subclinical CCM to improve the outcome for those with HIVassociated CCM.

\section{Introduction}

Cryptococcus meningitis is caused by Cryptococcus neoformans, an encapsulated yeast-like organism ubiquitous in the environment. ${ }^{1,2}$ Although exposed to $C$. neoformans pathogens, most people with a normal immune system do not acquire this infection. However, those with a lowered immune response are susceptible to cryptococcal infection, which has a particular tropism for the central nervous system, frequently causing fatal cryptococcal meningitis (CCM). ${ }^{3}$ This is a common opportunistic infection in Southeast Asia and sub-Saharan Africa, ${ }^{1}$ and is an Acquired Immune Deficiency Syndrome (AIDS)-defining illness in patients with late-stage HIV infection. It remains a major cause of HIV-related mortality worldwide with the largest burden of the disease being in sub-Saharan Africa, where health care access is often limited. ${ }^{4,5,6}$

South Africa (SA) has the largest HIV epidemic in the world, with approximately 7.06 million South Africans living with the virus in 2017 (12.6\% of the total South African population). ${ }^{7}$ Since 2004, the antiretroviral therapy (ART) programme in SA has grown considerably, and by 2016, it was estimated that 3929000 (56\%) people living with HIV (PLWHIV) were on treatment. ${ }^{8,9}$ In 2015, SA adopted the United Nations AIDS 90-90-90 ambitious but achievable treatment targets to help end the AIDS epidemic by 2020. In this programme, it is expected that $90 \%$ of the South African population will be aware of their HIV status; $90 \%$ of those who test positive will be on ART, and $90 \%$ of those who are on ARTs will be virally supressed by 2020 .

Despite these ambitious goals and the increased coverage of ART in SA, the incidence of HIVassociated CCM remains high with a case-fatality rate ranging between $30 \%$ and $50 \%{ }^{2,4,10,11}$ There is a high susceptibility to cryptococcal infection and the subsequent development of CCM among patients with a CD4 count $\leq 100$ cells $/ \mathrm{mm}^{3}$ as well as a high associated mortality. ${ }^{12,13}$ Therefore, 
in 2011, the World Health Organization (WHO) recommended that prior to initiating ART in populations with a high prevalence of cryptococcal $(\mathrm{Cr})$ antigenaemia, all ART-naïve adults with a CD 4 count $\leq 100$ cells $/ \mathrm{mm}^{3}$ should be routinely screened. People with evidence of cryptococcal disease should then be assessed for evidence of CCM and treated when positively diagnosed. ${ }^{14,15}$

In 2014, the South African Department of Health adopted the WHO recommendations, ${ }^{14}$ and a screen-and-treat intervention was added to the South African HIV guidelines ${ }^{16}$ which require that all HIV-positive patients with a $\mathrm{CD} 4 \leq 100$ cells $/ \mathrm{mm}^{3}$ be screened for $\mathrm{Cr}$ antigenaemia. All those who are $\mathrm{Cr}$ antigen positive $(\mathrm{CrAg}+\mathrm{ve})$ should be assessed for CCM, and those with symptoms suggestive of CCM should have a lumbar puncture (LP) and be treated if the diagnosis is confirmed. The purpose of this proactive screenand-treat intervention is to reduce CCM-related deaths. ${ }^{10,16}$

The aim of this study was to assess the effectiveness of the current screen-and-treat intervention for HIV-positive patients with a CD4 count $\leq 100$ cells $/ \mathrm{mm}^{3}$ who presented for care either at a large regional hospital in Durban or at a clinic that referred patients to the hospital, during 2015 and 2016.

\section{Methods}

Prince Mshiyeni Memorial Hospital (PMMH) is a 1200-bed regional hospital situated on the outskirts of Umlazi Township, Durban, and serves a population of approximately 2 million people with an estimated HIV prevalence of $16.9 \% .{ }^{17}$ There are 17 clinics in the hospital 'catchment area' that refer the patients to the hospital. All laboratory investigations (bloods, cerebrospinal fluid [CSF], etc.) from these clinics and PMMH hospital are sent to the National Health Laboratory Service (NHLS) laboratory based at the hospital for analysis. In accordance with the National HIV guidelines, all HIVpositive patients presenting to any of the 17 clinics or to PMMH must have a baseline CD4 count, and those specimens where the CD4 count is $\leq 100$ cells $/ \mathrm{mm}^{3}$ are reflexively screened for the presence of $\mathrm{CrAg}$ using the same blood specimen. Those patients who are $\mathrm{CrAg}+\mathrm{ve}$ are assessed by the clinicians for symptoms suggestive of CCM (headache, photophobia and/or confusion), and if symptomatic, are offered an LP to rule it out as part of the screen-and-treat intervention.

This study was divided into two parts, the first being a review of the data from the NHLS laboratory at PMMH of all those with a CD4 count $\leq 100$ cells $/ \mathrm{mm}^{3}$. This was followed by the second part, which was a review of the hospital records of all patients referred for an LP for suspected CCM and all those admitted to the hospital with confirmed CCM.

\section{Part A: National Health Laboratory Service data review}

The data for all HIV-positive patients older than 12 years of age seen at PMMH or the clinics who had a CD4 count $\leq 100$ cells $/ \mathrm{mm}^{3}$ between June 2015 and May 2016 were accessed from the NHLS laboratory records. These records were reviewed to determine the prevalence of $\mathrm{Cr}$ antigenaemia, and to match the data from the screened population against that of patients admitted to $\mathrm{PMMH}$ for an LP or CCM management using name, surname outpatient $(\mathrm{OP})$ and/or inpatient number, age and date of admission.

\section{Part B: Hospital records}

All of the ward admission books from all of the adult medical wards at $\mathrm{PMMH}$ were reviewed by the principal investigator. The records of all patients ( $\geq 12$ years) admitted for suspected meningitis were retrieved from the hospital records and reviewed in detail. Only the files of those patients who had an LP for suspected symptomatic CCM, and those with a confirmed diagnosis based on the CSF results between June 2015 and May 2016, were included in the study. A standardised data collection sheet was used to record age, gender, weight, symptoms of meningitis, CD4 count, ARTs duration, previous conditions, symptomatic presentation or screening, CSF results, Amphotericin B duration, complications, outcome (death, discharge) and length of stay (recorded in days). The records were reviewed carefully to establish if patients were referred to the hospital because of the screening process or whether they presented to the hospital because of symptoms suggestive of CCM (self-presented to the hospital). Data were entered using a Microsoft Excel Software package and analysed descriptively using the IBM SPSS Statistical Software, version 25. The Fisher's exact test was used for categorical data and the independent sample $T$ test was used for the numerical data with the level of significance being set at 0.05 .

\section{Ethical Considerations}

Ethical approval for the study was granted by Biomedical Research Ethic Committee (BREC REF No: BE402/16) of the University of KwaZulu-Natal (UKZN). Permission to conduct the study was granted by Prince Mshiyeni Memorial Hospital (PMMH) management and National Health Laboratory Service (NHLS) management.

\section{Results}

\section{Part A: National Health Laboratory Service data review}

Based on the retrieved NHLS laboratory results, 3702 patients aged between 12 and 86 years with a CD 4 count $\leq 100$ cell $/ \mathrm{mm}^{3}$ were seen at the clinics or hospital between June 2015 and May 2016. The mean age of these patients was $35 \pm 9.8$ years, male patients represented $49.9 \%$ (1847 out of 3702) of the population and the mean age of male patients was older (mean age $36 \pm 9.31$ years) than female patients (mean age $33 \pm 10.1$ years) with $p=0.001$. The CD4 counts ranged between 1 and 100 cells $/ \mathrm{mm}^{3}$ (mean $\left.=48.3 \pm 28.7\right)$, with male patients having a lower mean CD4 count (mean CD4 $=47 \pm$ 28.4) than female patients (mean CD4 $=50 \pm 28.9$ ) with $p=0.003$, a summary of those who were CrAg +ve and -ve being presented in Table 1. Patients who were CrAg +ve 
had significantly lower CD4 counts (mean CD4 = 38.9, SD 28.5) compared to the CrAg -ve patients (mean CD4 = 49.9, SD 37.4) with $p=0.0001$.

Figure 1 shows the flow of patients with a CD4 count $\leq 100$ cells $/ \mathrm{mm}^{3}$ who were screened for CrAg. In total, 3702 patients had a CD4 count $\leq 100$ cells $/ \mathrm{mm}^{3}$, of whom 3512 (94.9\%) were CrAg -ve, and 190 (5.1\%) were CrAg +ve, of whom $43(22.6 \%)$ were admitted either as a result of screening or who self-presented with symptoms of CCM.

Based on the data collected from the NHLS at PMMH, only five patients ( 5 out of $43 ; 11.6 \%$ ) with a CD $4 \leq 100$ cells $/ \mathrm{mm}^{3}$ had evidence of an LP performed at the hospital as part of screen-and-treat intervention, none of whom were diagnosed with CCM. The remaining $38(88.4 \%)$ patients who had an LP all self-presented to PMMH hospital with symptoms of meningitis (Table 2), and all had LP evidence of CCM based on CSF Cryptococcal latex antigen test (CLAT) and/or culture results. These patients are included in the 80 patients who self-presented to the hospital (Figure 2). Although the

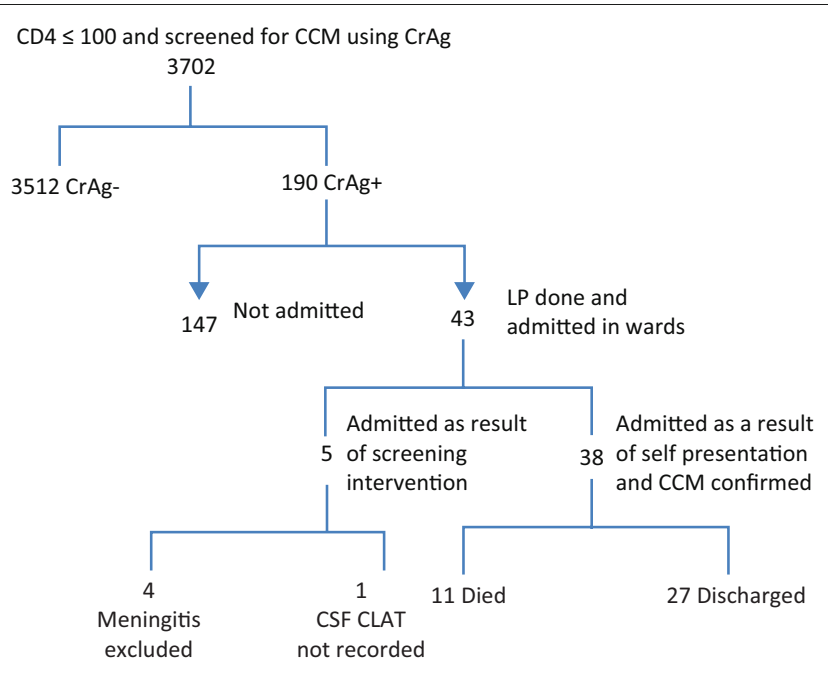

LP; lumbar puncture, CCM; cryptococcal meningitis, CSF, cerebrospinal fluid; CLAT, cryptococcal latex antigen test; serum $\mathrm{CrAg}$, serum cryptococcal antigen.

FIGURE 1: Flow diagram of patients with CD4 count $\leq 100$ cells $/ \mathrm{mm}^{3}$ who were screened for cryptococcal meningitis. laboratory and hospital records were extensively reviewed, no evidence could be found to indicate that any of the other $147(77.4 \%) \mathrm{CrAg}$ +ve patients had an LP or had been assessed for meningitis.

\section{Part B: Review of hospital records}

Between June 2015 and May 2016, 80 patients were admitted to $\mathrm{PMMH}$ (this includes the 38 patients in Figure 1 who self-presented) and treated for HIV-associated CCM of whom $57(71.3 \%)$ had a CD4 count $\leq 100$ cells $/ \mathrm{mm}^{3}, 10$ patients had a CD4 count $>100$ cells $/ \mathrm{mm}^{3}$ and 13 did not have their CD4 count recorded (Figure 3 and Table 3). Most patients who were admitted complained of headache (88.6\%), photophobia (60\%) and/or confusion $30.7 \%$.

The mean age of patients admitted with CCM was $34.6 \pm 6.9$ years (range 21-52 years). All patients with CSF evidence of CCM were treated with Amphotericin B $(0.7 \mathrm{mg} / \mathrm{kg}-1 \mathrm{mg} /$ $\mathrm{kg}$ ) for two weeks together with a high dose of fluconazole. A plan for initiating ARTs four weeks post- discharge was made if patients were not already on ARTs. Besides the 80 patients who had confirmed CCM on CSF, eight were admitted as a result of the screen-and-treat intervention who had LPs. However, only five of these appeared in the PMMH NHLS CrAg results record, and it is possibly that the other three came from outside the PMMH catchment area. None of the screened patients had confirmed CCM on LP.

In total, 30\% (24 out of 80 ) of patients admitted with CCM died, of those whose CD4 was $\leq 100$ cell $/ \mathrm{mm}^{3}, 31.6 \%$ (18 out of 57) died, whilst of those with a CD $4>100 \mathrm{cell} / \mathrm{mm}^{3}, 20 \%$ ( 2 out of 10) died, as did 30.8\% (4 out of 13) of those whose CD4 count was unknown. On average, the patients who died had a lower CD4 count (mean CD4 count $=40.35 \mathrm{cell} / \mathrm{mm}^{3} \pm$ $36.5 \mathrm{cell} / \mathrm{mm}^{3}$ ) than those who were discharged (mean CD4 count $=54.0$ cell $/ \mathrm{mm}^{3} \pm 60.1 \mathrm{cell} / \mathrm{mm}^{3}$ ) with $p=0.237$ (see Table 4).

\section{Discussion}

In the NHLS component of the study, 3702 patients presented for care at PMMH and the 17 clinics between June

TABLE 1: Summary of the CD4 count and viral load of patients with a CD4 count $\leq 100$

\begin{tabular}{|c|c|c|c|c|c|c|c|c|c|}
\hline & \multirow[t]{2}{*}{ Number } & \multicolumn{2}{|c|}{ Male patients } & \multicolumn{2}{|c|}{ Female patients } & \multicolumn{2}{|c|}{ Mean CD4 count } & \multicolumn{2}{|c|}{ Mean viral load } \\
\hline & & $n$ & $\%$ & $n$ & $\%$ & cells $/ \mathrm{mm}^{3}$ & $p$-value & copies/mL & $p$-value \\
\hline Antigen +ve & 190 & 115 & 60.5 & 75 & 39.5 & $38 \pm 28.5$ & - & $195182 \pm 341002$ & - \\
\hline Antigen -ve & 3512 & 1731 & 49.3 & 1781 & 50.7 & $49 \pm 37.4$ & - & $207126 \pm 597814$ & - \\
\hline Total & 3702 & 1847 & 49.9 & 1856 & 50.1 & - & $<0.0001$ & - & 0.879 \\
\hline
\end{tabular}

TABLE 2: Patients with CD4 $\leq 100$ whose cryptococcal antigen was positive and who were admitted to Prince Mshiyeni Memorial Hospital where a lumbar puncture was performed $(n=43)$.

\begin{tabular}{|c|c|c|c|c|c|c|c|}
\hline & \multicolumn{3}{|c|}{ Admitted as a result of screened $(n=5)$} & \multicolumn{3}{|c|}{ Self-presented with symptoms suggestive of CCM $(n=38)$} & \\
\hline & $n$ & $\%$ & mean & $n$ & $\%$ & mean & \\
\hline Female & 1 & 20 & - & 14 & 36.8 & - & 0.643 \\
\hline Male & 4 & 80 & - & 24 & 63.2 & - & 0.643 \\
\hline Age & - & - & $35 \pm 10$ & & $34 \pm 6$ & - & 0.796 \\
\hline CD4 count (cells $/ \mathrm{mm}^{3}$ ) & $16 \pm 16$ & - & - & $38 \pm 25$ & & - & 0.043 \\
\hline Viral load (copies/mL) & $181025 \pm 37232$ & - & - & $130696 \pm 136003$ & & - & 0.301 \\
\hline
\end{tabular}

CCM, cryptococcal meningitis. 


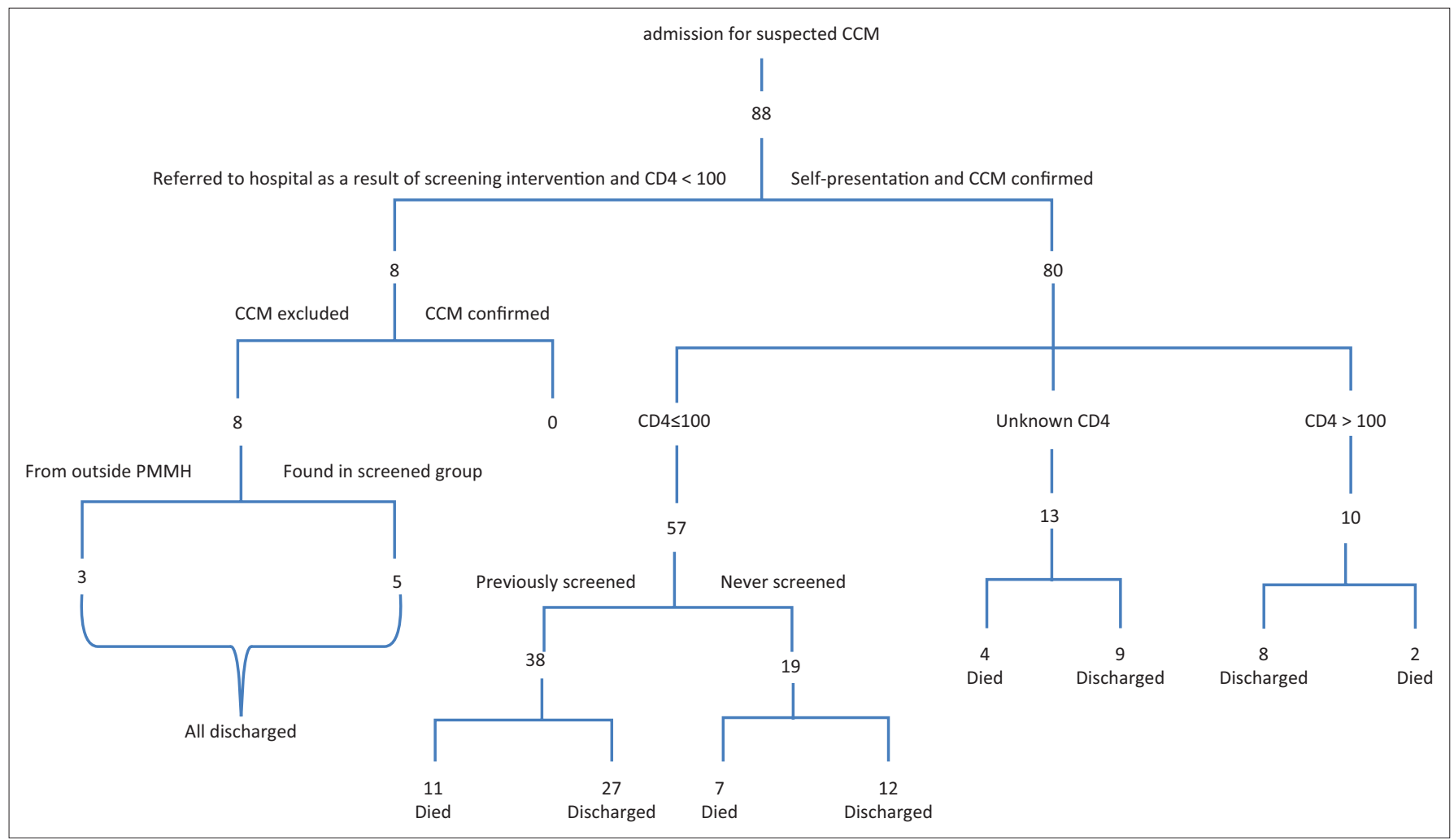

FIGURE 2: Flow diagram of patients admitted to Prince Mshiyeni Memorial Hospital for suspected cryptococcal meningitis.

TABLE 3: Summary of the patients admitted with confirmed cryptococcal meningitis $(N=80)$.

\begin{tabular}{|c|c|c|c|c|c|c|c|c|c|}
\hline \multirow[t]{2}{*}{ CD4 count } & \multirow[t]{2}{*}{ No. } & \multirow[t]{2}{*}{$\%$} & \multicolumn{2}{|c|}{ Male patients } & \multicolumn{2}{|c|}{ Female patients } & \multicolumn{2}{|c|}{ Age in years } & \multirow[t]{2}{*}{ CD4 mean cell $/ \mathrm{mm}^{3}$} \\
\hline & & & $n$ & $\%$ & $n$ & $\%$ & Mean & Range & \\
\hline$\leq 100$ cells $/ \mathrm{mm}^{3}$ & 57 & 71.2 & 35 & 67.3 & 22 & 78.6 & $34 \pm 6.875$ & $21-52$ & $37 \pm 27.4$ \\
\hline Unknown & 13 & 16.3 & 11 & 21.2 & 2 & 7.1 & $35 \pm 7.263$ & $24-47$ & - \\
\hline$>100$ cells $/ \mathrm{mm}^{3}$ & 10 & 12.5 & 6 & 11.5 & 4 & 14.3 & $38 \pm 5.959$ & $30-49$ & $155.1 \pm 74.2$ \\
\hline Total & 80 & & 52 & - & 28 & - & $35 \pm 6.911$ & $21-52$ & $55 \pm 56.484$ \\
\hline
\end{tabular}

No, number

TABLE 4: Outcome profile of patients admitted with cryptococcal meningitis $(N=80)$.

\begin{tabular}{|c|c|c|c|c|c|c|}
\hline \multirow[t]{2}{*}{ CD4 count (cells/mm $\mathrm{mm}^{3}$ ) } & \multicolumn{3}{|c|}{ Profile of patients who died $(n=24)$} & \multicolumn{3}{|c|}{ Profile of patients who were discharged $(n=56)$} \\
\hline & Number & $\%$ & Mean CD4 count & Number & $\%$ & Mean CD4 count \\
\hline$\leq 100$ & 18 & 31.6 & $31.72 \pm 26.437$ & 39 & 68.4 & $37.0 \pm 27.4$ \\
\hline$>100$ & 2 & 20 & $118 \pm 8.4$ & 8 & 80 & $155.1 \pm 74.2$ \\
\hline Unknown & 4 & 30.8 & - & 9 & 69.2 & - \\
\hline Total & 24 & 30 & $40.35 \pm 36.5$ & 56 & 70 & $54.0 \pm 60.1$ \\
\hline
\end{tabular}

2015 and May 2016 with a CD $4 \leq 100$ cells $/ \mathrm{mm}^{3}$. Although progress is being made towards achieving the 90-90-90 targets, many patients continue to present late in the progression of the disease. The findings of a recent study showed that $85.5 \%$ of HIV-positive South Africans were aware of their status, ${ }^{9}$ and as ARTs have been widely available since 2004, it is a concern that so many patients continue to present only when their HIV is at an advanced stage. These findings suggest that despite extensive publicity to encourage people to test early and regularly for HIV and to know their status, many only become aware of their HIV status when they develop symptoms, by which time their CD4 counts are likely to be very low. Since the early 1990s, considerable resources have gone into HIV campaigns encouraging safe sexual behaviour and the importance of knowing one's status. However, it would appear that a more nuanced understanding of the factors influencing when people choose to test for HIV and wish to start treatment is needed if all members of the population are to be encouraged to test early to know their HIV status and access ART.

In this study, only $5.1 \%$ (190 out of 3702) of the patients with a CD4 count of $\leq 100 \mathrm{cell} / \mathrm{mm}^{3}$ had $\mathrm{Cr}$ antigenaemia. These findings are higher than the $2.1 \%$ with $\mathrm{Cr}$ antigenaemia reported from a study in Soweto, ${ }^{18}$ consistent with studies in SA and UK, ${ }^{19,20,21}$ lower than the $13 \%$ reported from a 2009 study in Cape Town, ${ }^{2}$ and much lower than the $19 \%$ found in Uganda $^{22}$ and the $17.7 \%$ reported in Cambodia. ${ }^{23}$ With C. neoformans being ubiquitous in the environment, it is not clear why the percentage of patients with $\mathrm{Cr}$ antigenaemia varies widely between patients with a low CD4 count, and 
may have to do with the incidence of cryptococcal disease in the population being studied. ${ }^{18}$

Jarvis et al. reported that a negative CrAg was a $100 \%$ negative predictor for the development of CCM in patients with a low CD4 count. ${ }^{2}$ This is helpful for clinicians, as it means that among the 3512 patients who were $\mathrm{CrAg}$-ve in this study, there was no need to provide primary prophylaxis against CCM..$^{2,11,15}$ However, based on a cohort of patients tested in 2011, Govender et al. reported that a small number of patients ( 7 out of 1430; $0.5 \%$ ) developed CCM despite their initial CrAg being negative, ${ }^{18}$ as did Pongsa who reported that $0.8 \%$ (1 out of 119 ) of patients developed CCM despite having an initial $\mathrm{CrAg}$ that was negative. ${ }^{24}$ Govender concluded that these patients with very low CD4 counts developed CCM because of the delay in initiation of ARTs. The current South African guidelines recommend that all patients who are $\mathrm{CrAg}$-ve do not need primary prophylaxis with fluconazole, but need to be fast-tracked onto ARTs as the subsequent improvement in the CD4 count is the best defence against CCM. ${ }^{15,24}$

Cryptococcal antigen immunoassays have been shown to be effective in identifying patients at risk of developing subclinical cryptococcal infection before ART initiation..$^{2,25}$ Despite this, there is currently no consensus about how to manage patients who are $\mathrm{CrAg}+\mathrm{ve}$. The current South African HIV guidelines recommend that only those patients with symptoms suggestive of CCM should have an LP to confirm the diagnosis, and that those who are asymptomatic should receive high-dose fluconazole to prevent its development. ${ }^{15,24}$ Whilst a 2005 Cochrane review reported a reduction in the incidence of cryptococcal disease, there was no reduction in mortality associated with CCM from such approach. ${ }^{26}$

In this study, laboratory records show that only $2.6 \%$ (5 out of 190) of patients who were CrAg + ve had an LP at PMMH as part of the screening programme. In addition, no patient identified for an LP in this manner was diagnosed with CCM on LP, which suggests that clinicians were not effective in identifying patients with possible early onset of CCM. These results are very different from the findings from Gauteng province, where $41 \%$ (99 out of 244) of patients who were CrAg + ve were symptomatic, of whom 56 (57\%) had an LP and $59 \%$ (33 out of 56) were diagnosed with CCM. ${ }^{27}$ Furthermore, the study in Gauteng reported that $26 \%$ (8 out of 31 ) of the asymptomatic $\mathrm{CrAg}$ +ve patients had CCM on LP. ${ }^{27}$ Further studies are needed to understand the discrepancy between these findings, which may be because of the large patient load in Umlazi, the ad-hoc manner in which patients who are $\mathrm{CrAg}$ +ve are assessed for symptoms of CCM, or the challenges of referring patients from the clinics to the hospital. Additional research is needed to determine how to effectively screen patients with low CD4 counts for symptoms of CCM.

Alternative approaches to managing patients who are $\mathrm{CrAg}$ +ve include providing CrAg titres to help clinicians decide which patients require an $\mathrm{LP}^{2,24}$ or an LP for all patients who are $\mathrm{CrAg}$ +ve to exclude CCM, regardless of whether or not they are symptomatic. ${ }^{25}$ In a study in Thailand, where all patients who were $\mathrm{CrAg}$ +ve had an LP, 25\% (3 out of 12) of patients had active $\mathrm{CCM}^{24}$ whilst a retrospective review of patients who developed CCM in Cape Town showed that 28\% (13 out of 46 ) who were CrAg +ve developed CCM. ${ }^{2}$ A follow-up study in Gauteng in 2012-2014, among HIV patients with a CD4 count $\leq 100$ cells $/ \mathrm{mm}^{3}$ who were $\mathrm{CrAg}$ + ve, showed that $25 \%$ had subclinical CCM. ${ }^{27}$

Based on the review of hospital records, 20\% (38 out of 190) of patients who had been identified as $\mathrm{CrAg}$ +ve presented to the hospital with symptoms of CCM had their diagnosis confirmed LP. This finding is consistent with the study in Thailand, ${ }^{24}$ but much lower than the $66 \%-71 \%$ reported in earlier studies among patients with stage IV HIV disease. ${ }^{28,29}$ These 38 patients may represent those patients who were lost to follow-up, which is not an uncommon occurrence, ${ }^{18}$ or be a missed opportunity for early identification of CCM and initiation of treatment prior to the onset of obvious symptoms of CCM. In this study, the clinicians appeared to be unable, in the screening process, to identify those patients who went on to develop CCM. This suggests that patients with low CD4 counts who are $\mathrm{CrAg}$ + ve and who develop CCM either have no or very subtle symptoms that are not recognised as possible precursors to the development of CCM. However, there may be patients who go on to develop CCM once they have started on ARTs, as was the experience in the study in Cape Town. ${ }^{2,25}$ More research is needed to understand the early symptoms that might be predictive of CCM.

Cryptococcal meningitis continues to have a significant mortality, despite the introduction of high-dose fluconazole into the South African treatment guidelines. Based on the data available at PMMH, the overall mortality in this study was $30 \%$, which is consistent with other studies. ${ }^{6,11,18}$ It is important to note that the mortality was significantly higher in the cohort with a CD4 count $\leq 100$ cell $/ \mathrm{mm}^{3}(31.6 \%)$ and in the unknown CD4 cohort (30.8\%) than in those with a CD4 count $>100$ cell $/ \mathrm{mm}^{3}(20 \%)$, supporting the call to identify patients who are HIV-positive and to initiate ART before they develop profound immunological failure. This was not an unexpected finding, as many studies have linked CCMrelated mortality to a lower CD4 count. ${ }^{2,19,20,30}$

In the light of the high mortality associated with CCM, the challenges associated with early identification of subclinical CCM, the cost effectiveness of the screen-andtreat intervention (estimated to be cost-effective at a $\mathrm{CrAg}$ threshold of $0.6 \%),{ }^{18,20,30}$ the high pickup rate of CCM in asymptomatic CrAg +ve patients, ${ }^{24,27}$ as well as the resources available in SA, serious consideration should be given to recommending LPs for all patients with a low CD4 count who are $\mathrm{CrAg}+$ ve.

Although this study is limited by the small numbers, with $20 \%$ mortality in those patients whose CD4 count ranged 
between 101 and 150 cells $/ \mathrm{mm}^{3}$, consideration should include increasing the CD4 count level to 150 cells $/ \mathrm{mm}^{3}$ for patients who are screened for CrAg. In 2015, Govender et al. reported a $97 \%$ yield of incident antigenaemia when the CD4 threshold was increased from 100 cells $/ \mathrm{mm}^{3}$ to 150 cells $/ \mathrm{mm}, 3,18$ suggesting that this increase in the CD4 cutoff threshold may help to timely detect CCM in this group of patients. Further study is needed in this area as well as assessing the effect of giving patients who are CrAg +ve prophylactic fluconazole, in keeping with the current guidelines, to determine what impact this would have on the development of CCM.

\section{Limitations}

Because of the design of this study, it was not possible to follow up with patients who had Cryptococcus antigenaemia. Only a few patients were admitted for an LP following the screen-and-treat intervention, and the results need to be treated with caution. It is possible that some patients were referred but never presented to PMMH for LP and that some symptomatic patients were seen and managed at other health institutions, although the referral system is designed so that clinics in the Umlazi area refer patients to PMMH.

\section{Conclusions}

The current ad-hoc system at busy public sector clinics does not appear to be effective identifying and/or referring patients with subclinical symptoms of CCM nor in reducing its associated mortality. Although screening for $\mathrm{Cr}$ antigenaemia is considered to be cost-effective, the benefits are currently not being realised. This may be because of the challenges associated with identifying patients with latent or early CCM as well as the challenges within the health care system that include large numbers of patients, overloaded staff and the failure of patients to return for follow-up. Although this is a small descriptive study limited to one location, it does provide data based on day-to-day practice with caution being advised when interpreting the data. Based on the findings of this research, we recommend that a system be considered to ensure that all patients with $\mathrm{Cr}$ antigenaemia are offered an LP to exclude CCM, and that the cut-off point for assessing $\mathrm{Cr}$ antigenaemia be increased to a CD4 count of 150 cells $/ \mathrm{mm}^{3}$.

It is also very important that all patients with a low CD4 count be fast-tracked onto ARTs so as to reduce the risk of developing CCM. Further research is needed to assess the impact of these recommendations, and the effectiveness of other interventions aimed at reducing the mortality from CCM. This includes the use of oral fluconazole in patients who have $\mathrm{Cr}$ antigenaemia but not $\mathrm{CCM}$, and highdose fluconazole in combination with Amphotericin B for the management of CCM.

\section{Acknowledgements}

The authors would like to thank Prof. K.P. Mlisana (Associate Professor and Head of the Department of Medical
Microbiology) and Z. Mkhize (National Health Laboratory Service [NHLS] manager at Prince Mshiyeni Memorial Hospital) who helped to access all data needed from NHLS.

\section{Competing interests}

The authors declare that they have no financial or personal relationships that may have inappropriately influenced them in writing this article.

\section{Authors' contributions}

N.E. was responsible for writing the protocol, collecting and analysing the data and writing the article. A.R. made conceptual contributions and helped with the article writing.

\section{References}

1. Lee $\mathrm{Y}-\mathrm{C}$, Wang J-T, Sun H-Y, Chen $\mathrm{Y}-\mathrm{C}$. Comparisons of clinical features and mortality of cryptococcal meningitis between patients with and without human immunodeficiency virus infection. J Microbiol Immunol Infect. 2011;44(5): 338-345. https://doi.org/10.1016/j.jmii.2010.08.011

2. Jarvis JN, Lawn SD, Vogt M, Bangani N, Wood R, Harrison TS. Screening for cryptococcal antigenemia in patients accessing an antiretroviral treatment program in South Africa. Clin Infect Dis. 2009;48(7):856-862. https://doi.org/ 10.1086/597262

3. Srikanta D, Santiago Tirado FH, Doering TL. Cryptococcus neoformans: Historical curiosity to modern pathogen. Yeast. 2014;31(2):47-60. https://doi.org/10.1002/ yea.2997

4. Abassi M, Boulware DR, Rhein J. Cryptococcal meningitis: Diagnosis and management update. Curr Trop Med Rep. 2015;2(2):90-99. https://doi.org/ 10.1007/s40475-015-0046-y

5. Gaskell KM, Rothe C, Gnanadurai R, et al. A prospective study of mortality from cryptococcal meningitis following treatment induction with $1200 \mathrm{mg}$ oral fluconazole in blantyre, Malawi. PLoS One. 2014;9(11):e110285. https://doi.org/ 10.1371/journal.pone.0110285

6. Adeyemi BO, Ross A. Profile and acute mortality outcome of patients admitted with cryptococcal meningitis to an urban district hospital in KwaZulu-Natal, South
Africa. South Afr Fam Pract. 2015;57(2):131-135. https://doi.org/10.1080/20786 Africa. South Afr Fam
190.2014.976962

7. Statistical release: Mid-year population estimates for 2017 [homepage on the Internet]. Stats SA. 2017 [cited 2017 July 31]. http://www.statssa.gov.za/ publications/P0302/P03022017.pdf

8. Avert. HIV and AIDS in South Africa [homepage on the Internet]. Avert; 2016 [updated 30/10/2017]. Available from: https://www.avert.org/professionals/hivaround-world/sub-saharan-africa/south-africa [cited 2017 November 6]

9. Dorrington RE, Johnson LF, Moolla H. Progress towards the 2020 targets for HIV diagnosis and antiretroviral treatment in South Africa. South Afr J HIV Med. 2017;18(1):1-8.

10. Govender N, Dlamini S. Management of HIV-associated cryptococcal disease in South Africa. S Afr Med J. 2014;104(12) article summary p. 896. https://doi. org/10.7196/SAMJ.9070

11. Govender NP, Chetty V, Roy M, et al. Phased implementation of screening for cryptococcal disease in South Africa. S Afr Med J. 2012;102(12):914-917. https:// doi.org/10.7196/SAMJ.6228

12. Jarvis JN, Harrison TS, Govender N, et al. Routine cryptococcal antigen screening for HIV-infected patients with low CD4+ T-lymphocyte counts: Time to implement in South Africa? S Afr Med J. 2011;101(4):232-234. https://doi.org/10.7196/ SAMJ.4752

13. Cassim N, Schnippel K, Coetzee LM, Glencross DK. Establishing a cost-per-result of laboratory-based, reflex Cryptococcal antigenaemia screening $(\mathrm{CrAg})$ in $\mathrm{HIV}+$ patients with CD4 counts less than 100 cells/ $\mu$ l using a Lateral Flow Assay (LFA) at a typical busy CD4 laboratory in South Africa. PLoS One. 2017;12(2):e0171675. https://doi.org/10.1371/journal.pone.0171675

14. Chetchotisakd PC, Kumarasamy N, Govender NP, et al. Rapid advice: Diagnosis, prevention and management of cryptococcal disease in HIV-infected adults, adolescents and children. WHO, 2011Geneva Switzerland; p. 1-44.

15. Govender N, Meintjes G, Bicanic T, et al. Guideline for the prevention, diagnosis and management of cryptococcal meningitis among HIV-infected persons: 2013 update. South Afr J HIV Med. 2013;14(2):76-86. https://doi.org/10.4102/ sajhivmed.v14i2.82

16. DoH SA. National consolidated guidelines for the prevention of mother-tochild transmission of HIV (PMTCT) and the management of HIV in children, adolescents and adults. In: Health, editor. Pretoria: South African Department of Health, 2014; p. 119. http://www.sahivsoc.org/Files/ART\%20Guidelines $\% 20$ 15052015.pdf 
17. KZN. Universal Test-and-Treat 'A game changer in HIV prevention'. In: Health editor. KwaZulu-Natal: KZNonline; 2016. http://www.kznonline.gov.za/hivaids/ councils/Provincial-Councils-on-AIDS/2016/Universal\%20Test\%20\&\%20 Treat $\% 20$ Presentation.pdf

18. Govender NP, Roy M, Mendes JF, Zulu TG, Chiller TM, Karstaedt AS. Evaluation of screening and treatment of cryptococcal antigenaemia among HIV-infected persons in Soweto, South Africa. HIV Med. 2015;16(8):468-576. https://doi. persons in Soweto, Sout11/hiv.12245

19. Liechty CA, Solberg P, Were W, et al. Asymptomatic serum cryptococcal antigenemia and early mortality during antiretroviral therapy in rural Uganda. Trop Med In Health 2007:12(8):929-935. https://doi.org/10.1111/j.1365-3156.2007.01874.x

20. Meya DB, Manabe YC, Castelnuovo B, et al. Cost-effectiveness of serum cryptococcal antigen screening to prevent deaths among HIV-infected person with a CD4+ cell count $\leq 100$ cells/ $\mu$ L who start HIV therapy in resource-limited settings. Clin Infect Dis. 2010;51(4):448-455. https://doi.org/10.1086/655143

21. Patel S, Shin GY, Wijewardana I, et al. The prevalence of cryptococcal antigenemia in newly diagnosed HIV patients in a Southwest London cohort. J Infect. 2013;66(1):75-79. https://doi.org/10.1016/j.jinf.2012.09.014

22. Oyella J, Meya D, Bajunirwe F, Kamya MR. Prevalence and factors associated with cryptococcal antigenemia among severely immunosuppressed HIV-infected adults in Uganda: A cross-sectional study. J Int AIDS Soc. 2012;15(1):15. https:// doi.org/10.1186/1758-2652-15-15

23. Micol R, Lortholary O, Sar B, et al. Prevalence, determinants of positivity, and clinical utility of cryptococcal antigenemia in Cambodian HIV-infected patients. J Acquir Immune Defic Syndr. 2007;45(5):555-559. https://doi.org/10.1097/ QAl.0b013e31811ed32c
24. Pongsai P, Atamasirikul K, Sungkanuparph S. The role of serum cryptococcal antigen screening for the early diagnosis of cryptococcosis in HIV-infected patients with different ranges of CD4 cell counts. J Infect. 2010;60(6):474-477. https://doi. org/10.1016/j.jinf.2010.03.015

25. Jarvis JN, Govender N, Chiller T, et al. Cryptococcal antigen screening and preemptive therapy in patients initiating antiretroviral therapy in resourcelimited settings: A proposed algorithm for clinical implementation. JIAPAC 2012;11(6):374-379. https://doi.org/10.1177/1545109712459077

26. Chang LW, Phipps WT, Kennedy GE, Rutherford GW. Antifungal interventions for the primary prevention of cryptococcal disease in adults with HIV. Cochrane Database Syst Rev. 2005;2005(3):1-24. https://doi.org/10.1002/14651858. CD004773.pub2

27. Walaza S. Cryptococcal screen-and-treat in Gauteng province, South Africa: Update from the first two years of implementation, 2012-2014. Pretoria: Gauteng Province; 2014.

28. Desmet P, Kayembe KD, De Vroey C. The value of cryptococcal serum antigen screening among HIV-positive/AIDS patients in Kinshasa, Zaire. AIDS (London, England). 1989;3(2):77-78. https://doi.org/10.1097/00002030-19890200000004

29. Tassie JM, Pepper L, Fogg C, et al. Systematic screening of cryptococcal antigenemia in HIV-positive adults in Uganda. J Acquir Immune Defic Syndr. 2003;33(3):411-412. https://doi.org/10.1097/00126334-200307010-00019

30. Jarvis JN, Harrison TS, Lawn SD, Meintjes G, Wood R, Cleary S. Cost effectiveness of cryptococcal antigen screening as a strategy to prevent HIV-associated cryptococcal meningitis in South Africa. PLoS One. 2013;8(7):e69288. https://doi org/10.1371/journal.pone.0069288 